\title{
Significance of Perioperative Chemotherapy in Squamous Cell Carcinoma of the Upper and Lower Urinary Tract
}

\author{
TOMOYUKI MAKINO, KOUJI IZUMI, ARIUNBOLD NATSAGDORJ, HIROAKI IWAMOTO, SUGURU \\ KADOMOTO, RENATO NAITO, YOSHIFUMI KADONO and ATSUSHI MIZOKAMI \\ Department of Integrative Cancer Therapy and Urology, \\ Kanazawa University Graduate School of Medical Science, Kanazawa, Japan
}

\begin{abstract}
Background/Aim: To evaluate the clinicopathological characteristics and prognosis of squamous cell carcinoma (SCC) of the urinary tract (UT) urothelium, and investigate the utility of perioperative chemotherapy. Patients and Methods: Thirty-three patients diagnosed with SCC in renal pelvis, ureter and bladder at the Kanazawa University between 2007 and 2017 were included in this retrospective study. Cancer-specific survival (CSS) rates according to cancer stage and neoadjuvant chemotherapy (NAC) were determined. Results: Among the entire cohort, two-year CSS rates were $100 \%, 75 \%, 47 \%$ and $0 \%$ in stages I, II, III and IV, respectively, with a significant correlation between CSS and cancer stage ( $p=0.0063)$. Sixteen patients underwent radical surgery, and seven patients received $N A C$; however, there were no significant differences in CSS rates among patients stratified by NAC $(p=0.7043)$. Conclusion: Worse cancer stage for SCC of UT urothelium was associated with worse prognosis. Given the poor efficacy of NAC in these patients, surgical treatment should be preferred.
\end{abstract}

Although urothelial carcinoma (UC) represents the majority of bladder tumours, with rates ranging between $90 \%$ and 95\%, bladder cancer encompasses a wide spectrum of malignancies including squamous cell carcinoma (SCC; 2$5 \%)$, adenocarcinoma $(0.5-2 \%)$, small cell carcinoma $(<1 \%)$ and other less common histological types (1). In contrast,

This article is freely accessible online.

Correspondence to: Dr. Kouji Izumi, Department of Integrative Cancer Therapy and Urology, Kanazawa University Graduate School of Medical Science, 13-1 Takaramachi, Kanazawa, Ishikawa 920-8640, Japan. Tel: +81 762652393, Fax: +81 762344263, e-mail: azuizu2003@yahoo.co.jp

Key Words: Squamous cell carcinoma, squamous differentiation, renal pelvis, ureter, bladder.
SCC represents $1-2 \%$ of all upper urinary tract (UT) cancers; thus, establishing a standard of care for SCC is difficult and the prognosis remains poor due to the paucity of cases (2).

In this retrospective study, we evaluated the association between SCC of the upper and lower UT cases and oncological outcomes. We also surveyed the utility of perioperative chemotherapy in these cases.

\section{Patients and Methods}

For this institutional review board-approved retrospective study at the Kanazawa University, the medical records of 33 patients diagnosed with SCC in renal pelvis, ureter and bladder between 2007 and 2017 were included. We analysed cancer-specific survival (CSS) according to cancer stage, which was determined according to the TNM classification by the International Union Against Cancer (3). Histological type was determined according to the 2004 definition of the World Health Organization (4). Clinicopathological variables that were recorded included patient age, gender, tumour location, tumour $\mathrm{T}$ stage, lymph node ( $\mathrm{LN}$ ) status, presence of distant metastases, metastatic sites, cancer stage and histologic type (i.e. pure SCC or UC with squamous differentiation (UCSD)). In the present study, seven patients received presurgical treatment such as cisplatin-based chemotherapy including methotrexate/vinblastine/ doxorubicin/cisplatin (MVAC) or gemcitabine/cisplatin (GC) regimen. A grading system of histological response to neoadjuvant therapy for evaluation of both host reactions to tumour destruction and cytologic changes of tumour cells has been reported in various cancer types such as breast cancer; however, its utility in UC is unclear. Therefore, in this study, we utilized the grading system established for breast cancer to evaluate the efficacy of neoadjuvant chemotherapy (NAC). Overall survival (OS) and disease-free survival (DFS) rates were calculated from the date of diagnosis to death or last follow-up and occurrence of local or distant metastasis, respectively. Survival curves were calculated by the Kaplan-Meier method, and differences in survival between the groups according to the cancer stage were compared by log-rank test. Continuous variables were analysed using the Mann-Whitney $U$-test, and categorical variables were compared using the $\chi^{2}$ or Fisher's exact test. All tests with a two-sided $p$-value of $<0.05$ were considered statistically significant. All statistical analyses were performed using Prism 6 (GraphPad ${ }^{\circledR}$, USA). 
Table I. Patient characteristics at diagnosis.

\begin{tabular}{|c|c|}
\hline No. of patients & 33 \\
\hline \multicolumn{2}{|l|}{ Age, years } \\
\hline Median (range) & $77(44-86)$ \\
\hline \multicolumn{2}{|l|}{ Gender, n (\%) } \\
\hline Male & $20(60.6)$ \\
\hline Female & $13(39.4)$ \\
\hline \multicolumn{2}{|c|}{ Tumour location, n (\%) } \\
\hline Pelvis & $4(12.1)$ \\
\hline Ureter & $8(24.3)$ \\
\hline Bladder & $20(60.6)$ \\
\hline Pelvis/Bladder & $1(3.0)$ \\
\hline \multicolumn{2}{|l|}{ Diagnosis, n (\%) } \\
\hline Biopsy & $4(12.1)$ \\
\hline TUR-BT & $16(48.5)$ \\
\hline $\mathrm{RC}$ & $4(12.1)$ \\
\hline RNU & $9(27.3)$ \\
\hline \multicolumn{2}{|l|}{ Histology, n (\%) } \\
\hline SCC & $3(9.1)$ \\
\hline UCSD & $30(90.9)$ \\
\hline \multicolumn{2}{|l|}{ Tumour stage, n (\%) } \\
\hline $\mathrm{T} 1$ & $6(18.2)$ \\
\hline $\mathrm{T} 2$ & $7(21.2)$ \\
\hline $\mathrm{T} 3$ & $14(42.4)$ \\
\hline $\mathrm{T} 4$ & $6(18.2)$ \\
\hline \multicolumn{2}{|c|}{ LN involvement, $\mathrm{n}(\%)$} \\
\hline Yes & $5(15.2)$ \\
\hline No & $28(84.8)$ \\
\hline \multicolumn{2}{|c|}{ Distant metastasis, n (\%) } \\
\hline Yes & $5(15.2)$ \\
\hline No & $28(84.8)$ \\
\hline \multicolumn{2}{|l|}{ Stage, $\mathrm{n}(\%)$} \\
\hline I & $6(18.2)$ \\
\hline II & $5(15.2)$ \\
\hline III & $14(42.4)$ \\
\hline IV & $8(24.2)$ \\
\hline \multicolumn{2}{|l|}{ Metastatic site, $\mathrm{n}$} \\
\hline Paraaortic LNs & 3 \\
\hline Lung & 1 \\
\hline Bone & 1 \\
\hline Liver & 1 \\
\hline Retroperitoneum & 1 \\
\hline
\end{tabular}

TUR-BT: Transurethral resection of the bladder tumor; RC: radical cystectomy; RNU: radical nephroureterectomy; SCC: squamous cell carcinoma; UCSD: urothelial carcinoma with squamous differentiation; LN: lymph node.

\section{Results}

Patient characteristics are shown in Table I. Median age was 77 (range $=44-86$ years) years, and median follow-up duration was 405 (range $=7-4116$ days) days. Tumour locations were pelvis, ureter, pelvis/bladder and bladder in 4 $(12.1 \%), 8(24.3 \%), 1(3.0 \%)$ and $20(60.6 \%)$ patients, respectively. Pathological diagnosis was obtained by biopsy, transurethral resection of the bladder tumour, radical
Table II. Characteristics of patients who underwent radical surgery stratified by neoadjuvant chemotherapy (NAC).

\begin{tabular}{|c|c|c|c|}
\hline & $\begin{array}{c}\mathrm{NAC}(+) \\
(\mathrm{n}=7)\end{array}$ & $\begin{array}{c}\mathrm{NAC}(-) \\
(\mathrm{n}=9)\end{array}$ & $p$-Value \\
\hline Median age (years) & 65 & 77 & 0.011 \\
\hline Gender, n $(\%)$ & & & 1.000 \\
\hline Male & $5(71.4)$ & $7(77.8)$ & \\
\hline Female & $2(28.6)$ & $2(22.2)$ & \\
\hline Tumour location, n (\%) & & & 0.040 \\
\hline Pelvis & $1(14.3)$ & $2(22.2)$ & \\
\hline Ureter & $1(14.3)$ & $6(66.7)$ & \\
\hline Bladder & $5(71.4)$ & $1(11.1)$ & \\
\hline Grade, $\mathrm{n}(\%)$ & & & 0.596 \\
\hline G1-2 & $3(42.8)$ & $2(22.2)$ & \\
\hline G3 & $4(57.2)$ & $7(77.8)$ & \\
\hline Pathological T category, $\mathrm{n}(\%)$ & & & 0.550 \\
\hline$\leq \mathrm{pT} 2$ & $2(28.6)$ & $1(11.1)$ & \\
\hline$\geq \mathrm{pT} 3$ & $5(71.4)$ & $8(77.8)$ & \\
\hline Pathological N category, n (\%) & & & 0.493 \\
\hline $\mathrm{pN}-$ & $4(57.2)$ & $3(33.3)$ & \\
\hline $\mathrm{pN}+$ & 0 & $1(11.1)$ & \\
\hline $\mathrm{pNx}$ & $3(42.8)$ & $5(55.6)$ & \\
\hline Lymphovascular invasion, $\mathrm{n}(\%)$ & & & 1.000 \\
\hline Yes & $7(100)$ & $9(100)$ & \\
\hline No & 0 & 0 & \\
\hline Surgical margin, $\mathrm{n}(\%)$ & & & 0.585 \\
\hline Negative & $6(85.7)$ & $6(66.7)$ & \\
\hline Positive & $1(14.3)$ & $3(33.3)$ & \\
\hline Stage, n (\%) & & & 0.436 \\
\hline I & $1(14.3)$ & $1(11.1)$ & \\
\hline II & $1(14.3)$ & 0 & \\
\hline III & $3(42.8)$ & 7 (77.8) & \\
\hline IV & $2(28.6)$ & $1(11.1)$ & \\
\hline
\end{tabular}

cystectomy (RC) and radical nephroureterectomy (RNU) in $4(12.1 \%), 16(48.5 \%), 4(12.1 \%)$ and $9(27.3 \%)$ patients, respectively. Among 33 patients, 3 (9.1\%) and 30 (90.9\%) patients had pure SCC and UCSD, respectively. Of a total of 33 patients included in this study, 6 (18.2\%), 7 (21.2\%), 14 $(42.4 \%)$ and $6(18.2 \%)$ patients were in tumour stages T1, $\mathrm{T} 2, \mathrm{~T} 3$ and T4, respectively. According to the cancer stage, $6(18.2 \%), 5(15.2 \%), 14(42.4 \%)$ and $8(24.2 \%)$ patients had stage I, II, III and IV diseases, respectively. Five patients (15.2\%) had LN involvement, and five patients (15.2\%) had distant metastases such as the paraaortic LNs, lung, bone, liver and retroperitoneum.

Figure 1 shows the Kaplan-Meier curve for CSS rates stratified by cancer stage. There was a significant decline in survival rate with worsening cancer stage, with the 2-year CSS rates for stages I, II, III and IV as $100 \%, 75 \%, 47 \%$ and $0 \%$, respectively $(p=0.0063)$. There were ten patient deaths within the observation period, and the cause of death was cancer in nine patients. 


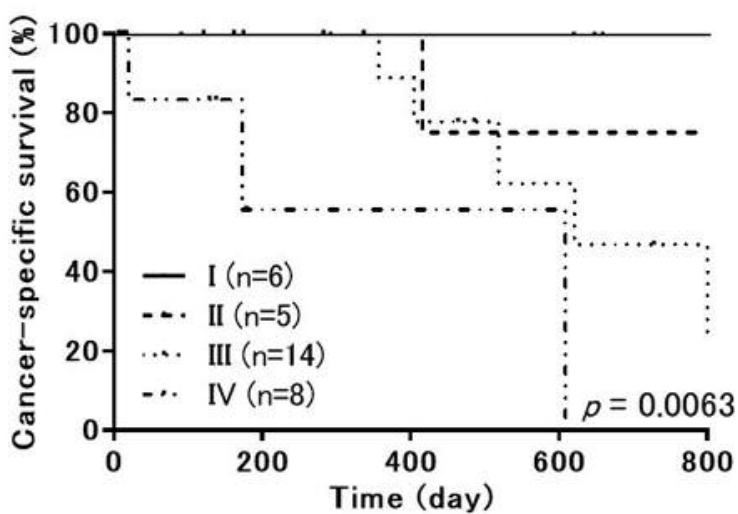

Figure 1. Cancer-specific survival rates for all patients stratified according to cancer stage.

Figure 2 shows the CSS and DFS rates for 16 patients who underwent RC or RNU. Median observation duration was 381 days, and median DFS was 292 days. The 2-year CSS and DFS rates were $68 \%$ and $35 \%$, respectively. In addition, seven patients who developed recurrent disease (e.g. local, regional $\mathrm{LN}$ or bladder) or metastasis (e.g. paraaortic LNs, lung), all of whom were stage III or higher, died due to cancer.

Table II shows characteristics of patients who underwent radical surgery and stratified by NAC. Radical surgery was performed in 16 patients, and seven patients received NAC. Of these seven patients, four and three patients received GC and MVAC regimens, respectively. As a result, age and tumour location were significantly different between the groups stratified by NAC, whereas there were no significant differences in sex, clinical grade, $\mathrm{T}$ category, $\mathrm{N}$ category, presence of lymphovascular invasion, or presence of a positive surgical margin.

Figure 3 shows CSS rates for patients who underwent radical surgery with or without NAC. The 2-year CSS rates for patients with or without NAC were $75 \%$ and $83 \%$, respectively $(p=0.7043)$. There were two cases which obtained histological therapeutic effect according to grading system of histological response to NAC (e.g. MVAC regimen). Both patients achieved cancer-free survival for more than five years, and one patient continued chemotherapy postoperatively. Furthermore, adjunctive postoperative treatment, including gemcitabine/carboplatin, GC, tegafur/uracil or external radiation, was administered in seven patients.

\section{Discussion}

Results from previous studies suggest that SCC of the bladder is more aggressive than UC of the bladder (5). Similarly, presence of variant histology might be associated

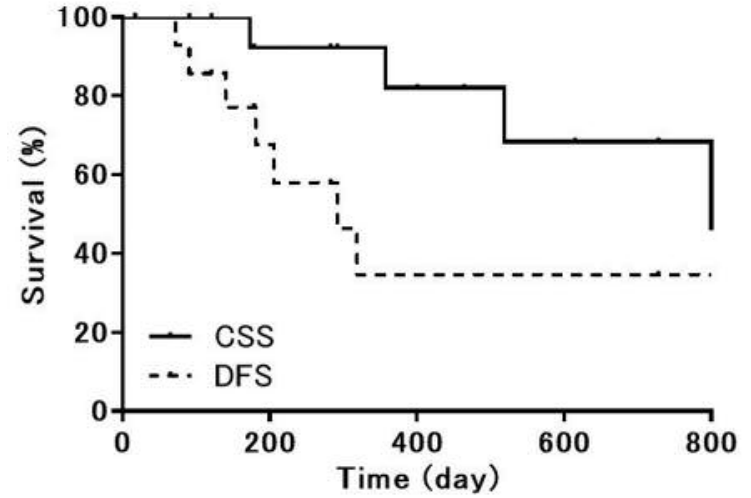

Figure 2. Cancer-specific survival (CSS) and disease-free survival (DFS) rates for patients who underwent radical surgery.

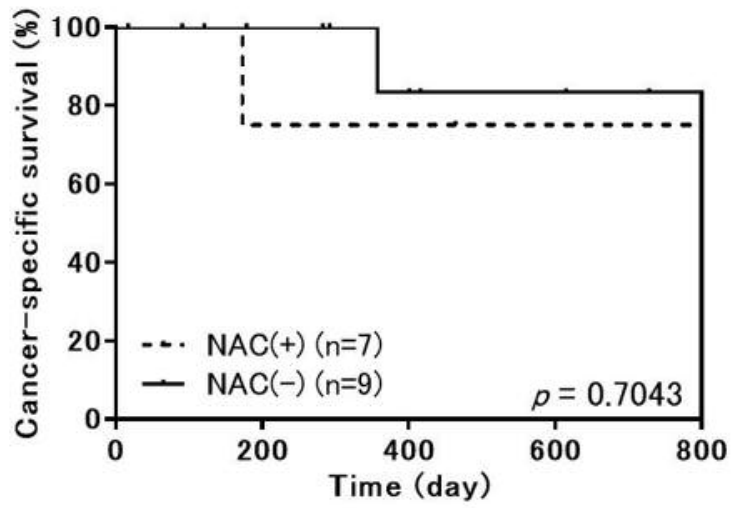

Figure 3. Cancer-specific survival rates for patients who underwent radical surgery with or without neoadjuvant chemotherapy (NAC).

with worse survival outcomes in patients with UC. Squamous and/or glandular differentiation is associated with features of biologically aggressive disease and an independent predictor of CSS (6). In the present study, SCC or UCSD in the upper and lower UT was diagnosed at a more advanced stage, and advanced stage was associated with worse prognosis. Similarly, Rausch et al. (7) reported that bladder SCC that were stage pT3 or higher was associated with worse prognosis. A similar observation was made for upper UT SCC, where clinical stage represents more aggressive disease compared to other histological types (2). In contrast, concomitant SCC component in biopsy specimen was an independent predictor of local recurrence after $\mathrm{RC}(8)$; in agreement with these earlier studies, we observed local recurrence after RC or RNU within the first year, as shown in Figure 2. Interestingly, bladder recurrence after RNU was reported to have a worse 
impact on prognosis (9). Therefore, an appropriate schedule of timely examinations is critical to prevent delay in identifying bladder recurrence after RNU.

Ehdaie et al. (10) found no statistically significant differences between survival curves of patients with SCC and UCSD who were treated with RC. However, compared with patients with UC, they reported that the CSS and OS rates were worse in both groups. Because many of the patients had UCSD in the present study, comparison with SCC was difficult; however, there appeared to be no difference in prognosis. Moreover, Ehdaie et al. (10) described that age, stage, lymphovascular invasion and presence of a positive surgical margin were significantly associated with CSS on multivariate analysis. However, we failed to determine a prognostic factor associated with CSS in patients treated with radical surgery in the present study (data not shown).

SCC is often described as refractory to chemotherapy (11). Although treatment with MVAC regimen was ineffective in patients with non-UC (12), Seretta et al. (13) performed a retrospective analysis of 19 patients with $\mathrm{SCC}$ and found that six patients were in complete remission after 52 months, four of whom were treated with NAC or adjuvant chemotherapy. Moreover, Galsky et al. (14) published a prospective study of patients with unresectable non-UC treated with ifosfamide, paclitaxel and cisplatin; the cohort included eight patients with pure SCC, and two patients achieved complete remission, indicating that long-term survival was possible. In the present study, although we did not find a significant difference in the 2-year CSS rates between patients who were treated with NAC and those who did not, we obtained histological therapeutic effect according to grading system in two of the seven patients who received NAC as presurgical treatment. Both patients achieved cancer-free survival for more than five years, but due to the very few cases, we could not evaluate the efficacy of NAC. However, this observation on the efficacy of NAC can be used for assessing whether patients should be administered postoperative adjuvant chemotherapy or treatment for recurrence. In contrast to the well-characterised platinum-based chemotherapy for advanced or metastatic UC $(12,15)$, sequential or alternative treatment after failure of platinum-based chemotherapy remains unclear. We previously reported that tegafur/uracil might be a candidate regime for the secondary treatment of advanced UC who fail platinumbased chemotherapy (16). Moreover, metastasectomy was reported as an independent significant predictor of better OS in patients with metastatic UC (17). Therefore, metastasectomy should be considered as a potential treatment for patients with metastatic SCC after RC or RNU.

In summary, based on the finding from previous reports and the current study, whether the efficacy of chemotherapy is restricted to SCC remains unclear. Hence, if local surgical control is achievable, radical surgery remains the first choice for treatment. Metastasectomy might be considered as a potential treatment in patients with metastasis or recurrence after radical surgery.

\section{Conclusion}

The presence of SCC in upper and lower UT was associated with advanced disease stage and a worse prognosis. However, evidence guiding the management of SCC is lacking due to the rarity of the disease. As this study illustrates, the efficacy of NAC or adjuvant chemotherapy in combination with radical surgery remains uncertain. Although we could not fully evaluate the efficacy of NAC, observation on the efficacy of NAC according to grading system can be used for assessing whether patients should be administered postoperative adjuvant chemotherapy or treatment for recurrence.

\section{Conflicts of Interest}

All Authors declare that there are no potential conflicts of interest relevant to this article.

\section{References}

1 Martin JW, Carballido EM, Ahmed A, Farhan B, Dutta R, Smith $\mathrm{C}$ and Youssef RF: Squamous cell carcinoma of the urinary bladder: Systematic review of clinical characteristics and therapeutic approaches. Arab J Urol 14: 183-191, 2016.

2 Berz D, Rizack T, Weitzen S, Mega A, Renzulli J and Colvin G: Survival of patients with squamous cell malignancies of the upper urinary tract. Clin Med Insights Oncol 6: 11-18, 2012.

3 Sobin LH, Gospodarowicz MK, Wittekind Ch (eds.). International Union Against Cancer (UICC) TNM Classification of Malignant Tumors. 7th ed. Oxford, UK, Wiley-Black-well, 2009.

4 Eble JN, Sauter G, Epstein JI and Sesterhenn IA: World Health Organisation classification of tumours. Tumours of the urinary system and male genital organs. IARC Press, Lyon, 2004.

5 Scosyrev E, Yao J and Messing E: Urothelial carcinoma versus squamous cell carcinoma of bladder: is survival different with stage adjustment? Urology 73: 822-827, 2009.

6 Lee YJ, Moon KC, Jeong CW, Kwak C, Kim HH, and Ku JH: Impact of Squamous and Glandular Differentiation on Oncologic Outcomes in Upper and Lower Tract Urothelial Carcinoma. PLoS One 9: e107027, 2014.

7 Rausch S, Hofmann R and von Knobloch R: Nonbilharzial squamous cell carcinoma and transitional cell carcinoma with squamous differentiation of the lower and upper urinary tract. Urol Ann 4: 14-18, 2012.

8 Honma I, Masumori N, Sato E, Takayanagi A, Takahashi A, Itoh $\mathrm{N}$, Tamagawa M, Sato MA and Tsukamoto T: Local recurrence after radical cystectomy for invasive bladder cancer: an analysis of predictive factors. Urology 64: 744-748, 2004.

9 Izumi K, Itai S, Takahashi Y, Takahashi R, Maolake A, Ofude M, Ueno S, Kadono Y, Kitagawa Y, Konaka H, Mizokami A and Namiki M: Factors predictive of oncological outcome after nephroureterectomy: comparison between laparoscopic and open procedures. Anticancer Res 33: 5501-5506, 2013. 
10 Ehdaie B, Maschino A, Shariat SF, Rioja J, Hamilton RJ, Lowrance WT, Poon SA, Al-Ahmadie HA and Herr HW: Comparative outcomes of pure squamous cell carcinoma and urothelial carcinoma with squamous differentiation in patients treated with radical cystectomy. J Urol 187: 74-79, 2012.

11 El-Sebaie M, Zaghloul MS, Howard G and Mokhtar A: Squamous cell carcinoma of the bilharzial and non-bilharzial urinary bladder: A review of etiological features, natural history, and management. Int J Clin Oncol 10: 20-25, 2005.

12 Sternberg CN, Yagoda A, Scher HI, Watson RC, Herr HW, Morse MJ, Geller N, Hollander PS, Lipperman R, Fair WR and Whitmore WF Jr.: M-VAC (methotrexate, vinblastine, doxorubicin and cisplatin) for advanced transitional cell carcinoma of the urothelium. J Urol 139: 461-469, 1988.

13 Serretta V, Pomara G, Piazza F and Gange E: Pure squamous cell carcinoma of the bladder in western countries. Report on 19 consecutive cases. Eur Urol 37: 85-89, 2000.

14 Galsky MD, Iasonos A, Mironov S, Scattergood J, Donat SM, Bochner BH, Herr HW, Russo P, Boyle MG and Bajorin DF: Prospective trial of ifosfamide, paclitaxel, and cisplatin in patients with advanced non-transitional cell carcinoma of the urothelial tract. Urology 69: 255-259, 2007.
15 von der Maase H, Sengelov L, Roberts JT, Ricci S, Dogliotti L, Oliver T, Moore MJ, Zimmermann A and Arning M: Long-term survival results of a randomized trial comparing gemcitabine plus cisplatin, with methotrexate, vinblastine, doxorubicin, plus cisplatin in patients with bladder cancer. J Clin Oncol 23: 46024608, 2005.

16 Maolake A, Izumi K, Takahashi R, Itai S, Machioka K, Yaegashi H, Nohara T, Kitagawa Y, Kadono Y, Konaka H, Mizokami A and Namiki M: Efficacy of tegafur-uracil in advanced urothelial cancer patients after the treatment failure of platinum-based chemotherapy. Anticancer Res 35: 1603-1606, 2015.

17 Iwamoto H, Izumi K, Shimura Y, Natsagdorj A, Maolake A, Takezawa Y, Nohara T, Shigehara K, Kadono Y and Mizokami A: Metastasectomy improves survival in patients with metastatic urothelial carcinoma. Anticancer Res 36: 5557-5561, 2016.

Received January 30, 2018

Revised February 18, 2018

Accepted February 20, 2018 